OPEN ACCESS

Edited by:

Jia-Yi Li,

Lund University, Sweden

Reviewed by:

Robert Fekete,

New York Medical College,

United States

Yinxia Chao,

National Neuroscience Institute

(NNI), Singapore

*Correspondence:

Yun-Cheng Wu

yunchw@medmail.com.cn

Huiyong Yin

hyyin@sibs.ac.cn

Specialty section:

This article was submitted to

Movement Disorders,

a section of the journal

Frontiers in Neurology

Received: 13 January 2021

Accepted: 10 March 2021

Published: 15 April 2021

Citation:

Li X, LiU T, Wu T-T, Feng Y, Peng S-J, Yin $\mathrm{H}$ and WU Y-C (2021) SIRT1 Deacetylates TET2 and Promotes Its Ubiquitination Degradation to Achieve Neuroprotection Against Parkinson's Disease. Front. Neurol. 12:652882. doi: 10.3389/fneur.2021.652882

\section{SIRT1 Deacetylates TET2 and Promotes Its Ubiquitination Degradation to Achieve Neuroprotection Against Parkinson's Disease}

\author{
Xuan Li ${ }^{1}$, Te Liu ${ }^{2}$, Ting-Ting Wu ${ }^{1}$, Ya Feng ${ }^{1}$, Si-Jia Peng ${ }^{1}$, Huiyong Yin ${ }^{3,4,5 *}$ and \\ Yun-Cheng $\mathrm{Wu}^{1 *}$
}

'Department of Neurology, Shanghai General Hospital, Shanghai Jiao Tong University School of Medicine, Shanghai, China, ${ }^{2}$ Shanghai Geriatric Institute of Chinese Medicine, Shanghai University of Traditional Chinese Medicine, Shanghai, China, ${ }^{3}$ CAS Key Laboratory of Nutrition, Metabolism and Food Safety, Shanghai Institute of Nutrition and Health, Chinese Academy of Sciences, Shanghai, China, ${ }^{4}$ Key Laboratory of Food Safety Risk Assessment, Ministry of Health, Beijing, China, ${ }^{5}$ School of Life Science and Technology, Shanghai Tech University, Shanghai, China

The epigenetic modifications, such as DNA methylation and histone acetylation, play a critical role in the pathogenesis of Parkinson's disease (PD). However, the relationship between DNA methylation and histone acetylation in PD is not fully understood. Previous studies have shown that patients with PD exhibit an epigenetic and transcriptional upregulation of Ten-Eleven Translocation 2 (TET2), a member of the DNA hydroxylases family. Silence information regulator 1 (SIRT1), a nicotinamide adenine dinucleotide (NAD)-dependent histone deacetylase, also plays a critical role in PD development and might be a potential target for PD therapy. Our previous data indicated that demethylation in the Cyclin-dependent kinase inhibitor 2A (CDKN2A) promoter by the TET2 directly activated its expression, then promoted the cell cycle arrest and cell death induced by 1-methyl-4-phenyl-pyridinium ion $\left(\mathrm{MPP}^{+}\right)$. In this study, we found that the enzyme activity of SIRT1 is negatively correlated with the protein level of TET2. In addition, the deacetylation of TET2 induced by SIRT1 promotes TET2 degradation via the ubiquitin-proteasome pathway. Furthermore, the activation of endogenous SIRT1 by resveratrol (RV) leads to CDKN2A DNA hypermethylation due to the decreased TET2 protein levels, which relieves the inhibitory effect on CDK4 and upregulation of $\mathrm{pRb}$, allowing cell proliferation and growth. Similar effects are observed for the inhibition of endogenous TET2 enzyme activity with TET2 inhibitor. Together, we discover a new mechanism by which the SIRT1-TET2-CDKN2A pathway is involved in the pathogenesis of PD, which may provide a potential target for PD treatment.

Keywords: Ten-Eleven Translocation 2, Silence information regulator 1, resveratrol, cyclin dependent kinase inhibitor 2A, Parkinson's disease 


\section{HIGHLIGHTS}

(1) Deacetylation of TET2 induced by SIRT1 promotes TET2 degradation via the ubiquitin-proteasome pathway.

(2) The CDKN2A/p16INK4a-CDK4-pRB signaling pathway is involved in the effect of TET2 on the cell cycle in the PD cellular model.

\section{INTRODUCTION}

Parkinson's disease (PD) is the second most common neurodegenerative disease, affecting about $1.0 \%$ of the population over 60 years of age and $3.0 \%$ of the population over 80 years of age (1). The pathogenesis of PD includes mitochondrial dysfunction, oxidative stress, inflammation, genetic factors, epigenetic modifications, etc. (2). However, the causative factors of neurodegenerative process affecting the etiopathogenesis of $\mathrm{PD}$ remain unknown (3).

Idiopathic $\mathrm{PD}$ is mediated by mutations in genes such as $\alpha$-synuclein, parkin, PTEN-induced kinase 1 , and leucinerich repeat kinase 2, protein DJ-1, but these account for only about $10 \%$ of $\mathrm{PD}$ patients (4). The majority of PD cases are sporadic, which is currently conceptualized as a consequence of various genetic variants and complex environment-gene interactions on a background of age-related changes adding up to individual levels of susceptibility (5). DNA modifications, particularly DNA methylation, show the most promise for epigenetic biomarker development in neurodegenerative diseases recently. Given the known influence of $\alpha$-synuclein expression levels in PD, initial DNA methylation studies focused on the SNCA gene. It has been reported that the methylation of human SNCA intron 1 decreased gene expression while the inhibition of DNA methylation activated its expression in the brains of PD patients (6). Although postmortem brain analysis revealed regional nonspecific methylation differences in this $\mathrm{CpG}$ region in the anterior cingulate and putamen among controls and PD, methylation was significantly decreased in the substantia nigra of PD patients (7). The results suggest that a decreased DNA methylation or increased demethylation maybe involved in the pathogenesis of PD.

DNA demethylation relies on the ten-eleven translocation (TET) enzyme to catalyze the conversion of DNA methylation to hydroxymethylation, which has also been shown to affect neurodevelopment and synaptic transmission (8). In mammals, the TET enzyme family includes TET 1, 2, 3. They have the same catalytic activity and can reverse DNA methylation by oxidizing 5-methylcytosine $(5 \mathrm{mC})$ to 5-hydroxymethylcytosine (5hmC) (9). $5 \mathrm{hmC}$ was found to be approximately $40 \%$ as abundant as $5 \mathrm{mC}$ in the DNA of Purkinje cells of the cerebellum,

\footnotetext{
Abbreviations: PD, Parkinson's disease; AD, Alzheimer's disease; TET2, Teneleven translocation 2; SIRT1, Silence information regulator 1; RV, Resveratrol; $5 \mathrm{mC}$, 5-methylcytosine; 5hmC, 5-hydroxymethylcytosine; Bax, Bcl-2-associated $\mathrm{X}$ protein; Bcl-2, B-cell lymphoma 2; $\mathrm{MPP}^{+}$, 1-methyl-4-phenyl-pyridinium ion; MPTP, 1-methyl-4-phenyl- 1,2,3,6-tetrahydropyridine; CDKN2A, cyclin dependent kinase inhibitor 2A; CDK4, cell cycle-dependent kinase 4; DA, dopaminergic; $\mathrm{Rb}$, retinoblastoma protein.
}

while the overall levels of $5 \mathrm{hmC}$ in the mammalian genome are $\sim 10 \%$ of the $5 \mathrm{mC}$ levels (10). Some research indicated that 5 hmC might play an important role in the occurrence and development of $\mathrm{AD}$ and $\mathrm{HD}(11,12)$. Gontier and colleagues have found that TET2 and $5 \mathrm{hmC}$ levels are decreased in the elderly hippocampus (13). Our previous study demonstrated the upregulation of TET2 in the cellular and animal model of PD, and further results indicated that TET2 knockdown attenuates 1-methyl-4-phenyl-1,2,3,6-tetrahydropyridine (MPTP)-induced behavioral impairments in mice (14). Another recent study also confirmed that, patients with PD exhibit an epigenetic and transcriptional upregulation of TET2, while TET2 depletion in a neuronal cell model results in cytosine modification changes that are reciprocal to those observed in PD neurons (15). Therefore, the widespread epigenetic dysregulation of enhancers in the PD cellular and animal model may be partly mediated by an increased TET2 expression or its activity. Suppressing the protein level or enzyme activity of TET2 in vivo has a neuroprotective effect and may have a substantial therapeutic potential for PD.

Other PD associated genes also seem to be regulated by histones modifications. There are higher levels of histone acetylation in the midbrain of dopaminergic (DA) neurons from PD patients compared to the controls (16). Silence information regulator 1 (SIRT1) is a nicotinamide adenine dinucleotide (NAD)-dependent histone deacetylase. It has been shown to regulate a variety of physiological and pathological processes, including metabolism, cell proliferation, cell differentiation, inflammatory immune response, oxidative stress, cell apoptosis, and other processes (17). In the adult brain, SIRT1 can modulate synaptic plasticity and memory formation (18). Singh et al. found that the enzymatic activity of SIRT1 is disturbed in patients with $\mathrm{PD}$, which may make these patients particularly susceptible to neurotoxin-induced neuronal damage (19). Based on the neuroprotective effects of SIRT1 on PD, many in vitro and in vivo experiments have demonstrated that some SIRT1 activators, notably resveratrol (RV), have potential neuroprotective effects against DA neuronal damage caused by various neurotoxins (20), but the specific molecular mechanism underlying its action requires further elucidation. Our team has also done some experiments to verify the protective effects of SIRT1 on PD, and discovered some neuroprotective pathways regulated by SIRT1 (21-24). Yet, whether TET2 is also regulated by SIRT1 in PD remains unclear.

A recent study of hematopoietic stem/progenitor cells (HSPC) in myelodysplastic (MDS) syndromes showed that the expression of SIRT1 and TET2 is down-regulated, and SIRT1 is fused to a lysine residue conserved in the TET2 catalytic domain, which enhances the methylation activity of TET2, inhibiting the abnormal proliferation of HSPC (25). Sun et al. recently reported that SIRT1 deacetylates TET2 in myelodysplastic syndrome stem and progenitor cells. Enhanced TET2 activity marked by $5 \mathrm{hmC}$ was observed in MDS CD34 ${ }^{+}$cells upon SRT1720 treatment (26). In this study, we investigated the role of these two epigenetic modifications in the pathogenesis of PD by exploring the relationship between SIRT1 and TET2. 


\section{MATERIALS AND METHODS}

\section{Cell Culture and Transfection}

SH-SY5Y neuroblastoma cells were cultured in Dulbecco's modified eagle's medium (DMEM, Gibco) containing 10\% fetal calf serum (Gibco, Brazil) and grown in a $\mathrm{CO}_{2}$ incubator maintained at atmospheric oxygen levels and $5 \% \mathrm{CO}_{2}$. Dissolved $\mathrm{MPP}^{+}$(Sigma Aldrich) in phosphate buffered saline (PBS) to a storage concentration of $125 \mathrm{mM}$. Resveratrol (Sigma) was prepared in dissolved dimethyl sulfoxide (DMSO) at a stock of 25 mM. EX-527, SRT1720, CHX, MG-132, Calpeptin, Z-VAD, and Bobcat339 (Selleckchem) stocks were dissolved in DMSO at the concentrations of $10 \mathrm{mM}, 10 \mathrm{mM}, 1 \mathrm{mg} / \mathrm{ml}, 10 \mathrm{mM}, 10 \mathrm{mM}$, $50 \mathrm{mM}$, and $3 \mathrm{mM}$, respectively. They were both stored at $-20^{\circ} \mathrm{C}$. Resveratrol, EX-527, and SRT1720 were pretreated cells $12 \mathrm{~h}$ before specific administration.

TET2 knockdown by lentiviral delivery of a short hairpin RNA (shRNA) was achieved via lentiviruses expressing the green fluorescent protein (GFP) and shRNA-TET2. shRNA-TET2 containing human shTET2a and shTET2b. Sequences for human shTET2a and shTET $2 b$ were (5'-GGGTAAGCCAAGAAAGAAA-3') and (5'-AAACAAAGAGCAAGAGATT-3'), respectively.

\section{CCK8 Cell Viability Assay}

The CCK-8 assay kit (Cell Counting Kit-8; Biomake) was used to determine cell viability. SH-SY5Y cells were seeded into 96-well plates at a density of 5,000 cells/well with $100 \mu \mathrm{l}$ of cell medium in each well. The cells were treated differently after they were firmly attached. After a certain processing time, $10 \mu \mathrm{l}$ of CCK8 working solution was added to each well to incubate for about $1 \mathrm{~h}$ at $37^{\circ} \mathrm{C}$. The wells containing only the culture medium served as blanks. The absorbance value at $450 \mathrm{~nm}$ was measured using a microplate reader.

\section{Cell Cycle Assays}

Cell cycle analysis was performed using a Cell Cycle and Apoptosis Analysis Kit (Beyotime). After treatment, the cells were washed with $\mathrm{PBS}$ and fixed in $70 \%$ pre-cooled ethanol at $4^{\circ} \mathrm{C}$ overnight. Thereafter, the cells were re-suspended in 500 $\mu \mathrm{l}$ of PBS containing $0.2 \mathrm{mg} / \mathrm{mL}$ RNase A, and then $50 \mu \mathrm{g} / \mathrm{mL}$ propidium iodide (PI) was added to stain the cells for $30 \mathrm{~min}$ in the dark at $37^{\circ} \mathrm{C}$. The percentages of cells at different phases (G0/G1, S, and G2/M) of the cell cycle were counted using a flow cytometer.

\section{Western Blot Analysis}

The samples were lysed using a cell lysis buffer along with protease inhibitors. Equal amount of the protein samples was first separated by SDS-PAGE and then transferred to polyvinylidene fluoride (PVDF) membranes. Membranes were blocked with 5\% non-fat milk in tris-buffered saline Tween (TBST) for $1 \mathrm{~h}$ at room temperature and then incubated overnight at $4{ }^{\circ} \mathrm{C}$ with specific primary antibodies: anti-rabbit TET2 (Abcam), antirabbit SIRT1, anti-rabbit p16INK4a, anti-mouse Tubulin, antimouse LaminB1, anti-mouse HA-tag (CST), anti-rabbit CDK4, anti-rabbit $\mathrm{pRb}$, anti-rabbit $\mathrm{Bax}$, anti-rabbit $\mathrm{Bcl}-2$, and antimouse GAPDH (Proteintech, United States). Then, the PVDF membranes were washed with TBST for three times and $10 \mathrm{~min}$ each time. Membranes were incubated with the corresponding secondary antibody horseradish peroxidase (HRP) conjugated at 1:5,000 dilution in 5\% non-fat milk/TBST for $1 \mathrm{~h}$ at room temperature. Then, the membranes were washed with TBST following the previous method. After washing three times, the bands were visualized by using the enhanced chemiluminescence (ECL) reagents and an $\mathrm{x}$-ray machine. The densitometric values of the bands were measured using the Image J software.

\section{Quantitative Real-Time Reverse Transcription Polymerase Chain Reaction (qRT-PCR)}

SH-SY5Y cells after specific treatment were washed with PBS. Total RNA in cells was extracted using the Trizol reagent (Invitrogen Life Technologies, Carlsbad, CA, United States) according to the manufacturer's instructions. All RNA samples were purified and reverse transcribed into complementary deoxyribonucleic acid (cDNA), and quantitative PCR analysis was performed as described (27). The primer sequences used were:

\section{TET2-F: 5' -ATTCTCGATTGTCTTCTCTAGTGAG-3'; TET2-R: 5' -CATGTTTGGACTTCTGTGCTC - $3^{\prime}$; 18sRNA-F: 5' -CAGCCACCCGAGATTGAGCA -3'; 18sRNA-R: 5' -TAGTAGCGACGGGCGGTGTG -3';}

\section{Nuclear and Cytoplasmic Separation}

The cells were planted in a $10 \mathrm{~cm}$ dish. Two dishes of cells were needed. When the cells are full, the culture medium was discarded, and $1 \times$ PBS was added to wash twice. The nuclear and cytoplasmic separation kit (Beyotime) was used to carry out the nuclear and cytoplasmic separation experiment. Refer to the kit instructions for specific experimental methods. Afterwards, the nucleoprotein uses LaminB1 as the control, and the cytoplasmic protein uses Tubulin as the control.

\section{Protein Immunoprecipitation}

Add $500 \mu \mathrm{l}$ of special cell lysis buffer for protein immunoprecipitation $(50 \mathrm{mM}$ Tris-HCL, $400 \mathrm{mM} \mathrm{NaCl}$, $0.8 \%$ Triton-100X, PH7.5) to $10 \mathrm{~cm}$ dish cells. Put the dish on ice for $30 \mathrm{~min}$, then scrape them and centrifuge at $12,000 \mathrm{rpm}$ for $10 \mathrm{~min}\left(4^{\circ} \mathrm{C}\right)$. Take the supernatant into a new $1.5 \mathrm{ml}$ centrifuge tube. Incubate with protein antibody at $4^{\circ} \mathrm{C}$ for $6 \mathrm{~h}$, then add protein A/G agarose beads, and incubate overnight at $4^{\circ} \mathrm{C}$. After that, use $1 \times$ TBS to wash the beads three times, add $1 \times$ loading buffer, heat at $95^{\circ} \mathrm{C}$ for $5 \mathrm{~min}$, centrifuge, and take the supernatant for western blot test.

\section{Cell Ubiquitination Test}

The cells were planted in a $10 \mathrm{~cm}$ dish, and Lipofectamine ${ }^{\circledR} 3000$ (Catalog L3000-015) was used to transfect the cells with HA-Ub plasmid, $48 \mathrm{~h}$ later, add MG-132 $(10 \mu \mathrm{M})$ for $6 \mathrm{~h}$, then discard medium, add $500 \mathrm{ml}$ cell lysate for protein immunoprecipitation (50 mM Tris-HCL, $400 \mathrm{mM} \mathrm{NaCl}, 0.8 \%$ Triton-100X, PH7.5) on ice for $30 \mathrm{~min}$, and centrifuge at $12,000 \mathrm{rpm}$ for $10 \mathrm{~min}\left(4^{\circ} \mathrm{C}\right)$. Take the supernatant into a new $1.5 \mathrm{ml}$ centrifuge tube and 
incubate with anti-rabbit TET2 (Abcam) at $4^{\circ} \mathrm{C}$ for $6 \mathrm{~h}$, then add protein $\mathrm{A} / \mathrm{G}$ agarose beads, and incubate overnight at $4^{\circ} \mathrm{C}$. Wash the beads three times with $1 \times$ TBS, add the loading buffer, heat at $95^{\circ} \mathrm{C}$ for $5 \mathrm{~min}$, centrifuge, and take the supernatant for western blot detection.

\section{Cellular Immunofluorescence}

Seed the cells in a six-well plate covered with glass slides to a density of $60-80 \%$. After the cells adhere to the wall, discard the culture medium and wash them with $1 \times$ PBS, and add $1 \mathrm{ml}$ of frozen methanol to fix at room temperature for $5 \mathrm{~min}$. Then, add $1 \mathrm{ml}$ of $1 \times$ PBS to wash for $5 \mathrm{~min}$, repeat twice, then add $1 \%$ Triton $\mathrm{X}-1001 \mathrm{ml}$ to break the membrane at room temperature. Wash with $1 \times \mathrm{PBS}$ for $5 \mathrm{~min}$. After washing twice, add $1 \mathrm{~mL}$ of $1 \%$ BSA at room temperature for $30 \mathrm{~min}$. After the cells and the primary antibody anti-rabbit TET2 (Abcam,
1:100) or anti-rabbit $5 \mathrm{hmc}(\mathrm{CST}, 1: 100)$ were co-incubated for $30 \mathrm{~min}$ at $37^{\circ} \mathrm{C}$, wash the cells with $1 \times$ PBS for three times, the corresponding secondary antibody Alexa-Fluor 594-conjugated anti-rat secondary antibody (Molecular Probes, diluted 1:100 in PBS) was incubated for $30 \mathrm{~min}$ at $37^{\circ} \mathrm{C}$ in the dark, dripped "prolong diamond antifade mountant with DAPI" (Invitrogen) at last. Finally, use the Zeiss LSM 780 to take pictures, and use the ZEN 2010 software (Zeiss) to analyze the pictures.

\section{Statistical Analysis}

Data were presented as mean $\pm \mathrm{SD}$ and each experiment was performed at least three times including the biological and technical replicates. The differences were evaluated using $t$-tests or two-way ANOVA using the GraphPad Prism software version 5. $P<0.05$ were considered statistically significant.

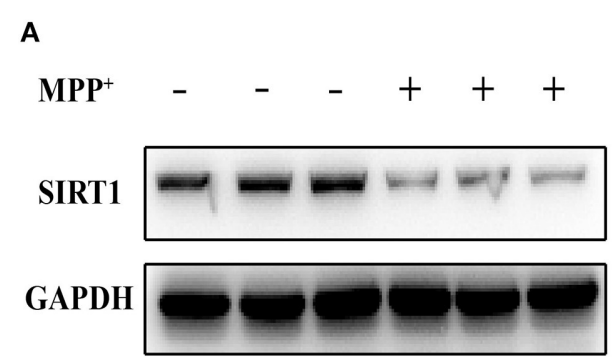

B

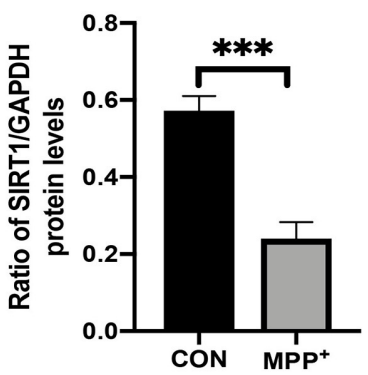

C
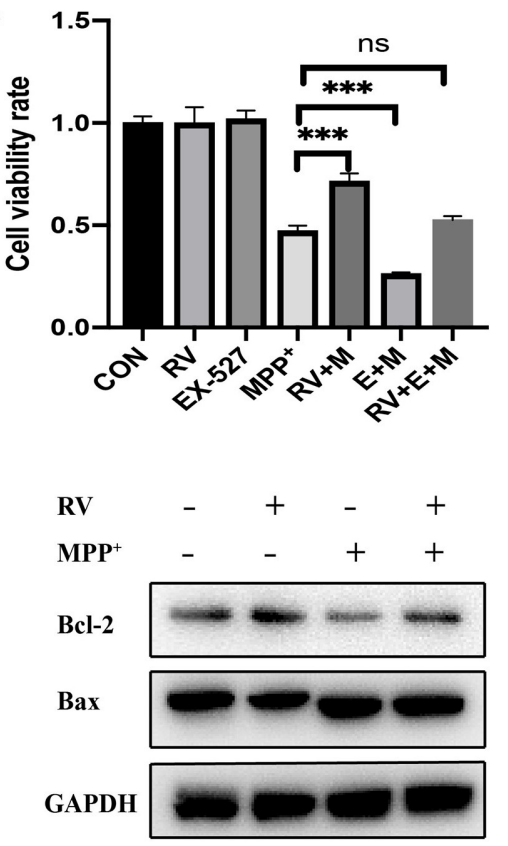

D
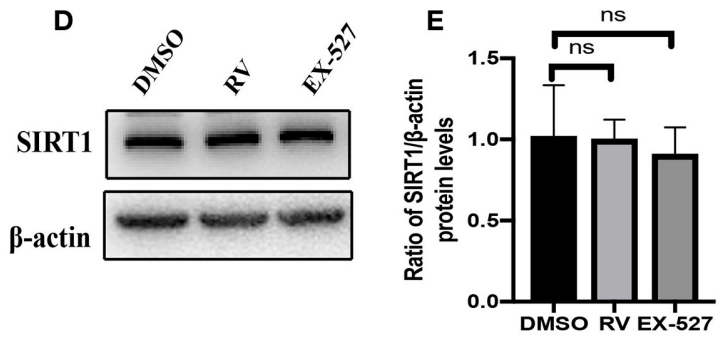

FIGURE 1 | Alleviation of MPP ${ }^{+}$-induced injury of SH-SY5Y cells by resveratrol. (A,B) SH-SY5Y cells were treated with MPP ${ }^{+}(2.5 \mathrm{mM})$ for $24 \mathrm{~h}$ and the protein level of SIRT1 was detected via western blot. (C) SH-SY5Y cells were treated with RV (resveratrol $25 \mu \mathrm{M})$, EX- $527(10 \mu \mathrm{M}) 12 \mathrm{~h}$ before M (MPP+, $2.5 \mathrm{mM}$ ) treated and then co-treated with two or three of them for $24 \mathrm{~h}$, then proliferation inhibition rates were examined by the CCK-8 method. (D,E) SH-SY5Y cells were treated with RV (resveratrol $25 \mu \mathrm{M})$, EX-527 $(10 \mu \mathrm{M})$ for $24 \mathrm{~h}$ and the protein level of SIRT1 was detected via western blot. (F,G) SH-SY5Y cells were treated with MPP+ $(2.5 \mathrm{mM})$, RV $(25 \mu \mathrm{M})$ separately, or were treated with RV $12 \mathrm{~h}$ before MPP ${ }^{+}$and then co-treated with MPP ${ }^{+}$for $24 \mathrm{~h}$. Western blot and quantification of protein was performed to detect apoptotic proteins. Data are shown as the mean $\pm \mathrm{SD}(n=3) ;{ }^{*} P<0.05,{ }^{\star \star \star} P<0.001$. 


\section{RESULTS}

\section{Alleviation of MPP ${ }^{+}$-Induced Injury of SH-SY5Y Cells by Resveratrol}

To determine whether SIRT1 was altered in the $\mathrm{MPP}^{+}$ treated cells, the protein levels of SIRT1 were detected by western blot following $\mathrm{MPP}^{+}$treatment. SIRT1 was significantly decreased after $\mathrm{MPP}^{+}$treatment at $24 \mathrm{~h}$ in our current study (Figures 1A,B). Next, we checked the effect of RV on cell viability and found that when cells were pre-treated with RV for $12 \mathrm{~h}, \mathrm{MPP}^{+}$-induced cell death was dramatically attenuated (Figure 1C). SH-SY5Y cells were treated with RV or EX-527 for $24 \mathrm{~h}$ and the protein level of SIRT1 was detected via western blot, the results showed that RV and EX-527 did not affect the protein level of SIRT1 (Figures 1D,E). To determine whether SIRT1 is involved in the neuroprotective effect of RV, we used EX-527 (specific inhibitor of SIRT1) to treat SH-SY5Y cells. The results showed that EX-527 may aggravate the cell damage caused by $\mathrm{MPP}^{+}$. Meanwhile, when the cells were treated with both EX-527 and RV, EX-527 can abolish the rescue effect of RV from $\mathrm{MPP}^{+}$ toxicity (Figure 1C). The ratio of B-cell lymphoma 2 protein (Bcl-2)/Bcl-2-associated $\mathrm{X}$ protein (Bax) protein regulates the sensitivity of cells to apoptosis: the higher this ratio is, the less sensitive the cells are to apoptosis. Our results also showed that pre-treatment with RV reversed the neurotoxicity of $\mathrm{MPP}^{+}$by promoting $\mathrm{Bcl}-2 / \mathrm{Bax}$ ratio, indicating that $\mathrm{RV}$ can reduce $\mathrm{SH}-$ SY5Y cells damage caused by neurotoxin through inhibiting apoptosis (Figures 1F,G). Taken together, our results suggested that RV decreased the cell death and apoptosis induced by $\mathrm{MPP}^{+}$, and this effect of RV was SIRT1-dependent.

\section{The Enzyme Activity of SIRT1 Is Negatively Correlated With the Protein Level of TET2}

We divided SH-SY5Y cells into CON (control) group, RV treatment group, $\mathrm{MPP}^{+}$treatment group, and $\mathrm{RV}$ and $\mathrm{MPP}^{+}$ co-treatment group. It showed that RV can inhibit the upregulation of TET2 expression in DA neurons caused by $\mathrm{MPP}^{+}$ (Figures 2A,B). In order to more accurately study the regulatory relationship between SIRT1 and TET2, we treated SH-SY5Y cells with SIRT1 specific agonist SRT1720 and inhibitor EX-527, neither agonists nor inhibitors of SIRT1 affect the mRNA level of TET2 (Figure 2C). However, the protein expression of TET2 was significantly reduced after different concentrations of SRT1720 treatment (Figures 2D,E); while different concentrations of EX-527 induced the protein expression of TET2 significantly (Figures 2F,G). The above results indicate that the enzyme activity of SIRT1 is negatively correlated with the protein level of TET2. We are also curious about whether changes in the TET2 protein expression affect the SIRT1 protein level, so we detect the protein level of SIRT1 after transfecting the cells with shTET2 lentivirus. The results show that the down-regulation of TET2 will also lead to the up-regulation of SIRT1 (Figures 2H,I). Taking these results into consideration, we think that TET2 is significantly increased during the development of $\mathrm{PD}$, and the activation of SIRT1 induced by RV can ameliorate the increase of TET2 in PD.

\section{Changes in Enzyme Activity of SIRT1 Affected the Functionality of TET2}

Since TET2 needs to interact with DNA binding partners to regulate gene expression in the nucleus $(28,29)$, we test whether SIRT1 activity affects the entry of TET2 into the nucleus and the level of 5hmc in SH-SY5Y cells. As shown in Figures 3A,B, immunofluorescence staining of TET2 (red) was conducted. Merged images showed that TET2 was both distributed in the cytoplasm and nucleus. After SIRT1 inhibition by EX-527, the protein level of TET2 increased and mainly accumulated in the nucleus. To further verify this phenomenon, we carried out nuclear and cytoplasmic separation of SH-SY5Y cells. Similarly, RV significantly decreased the level of TET2, whereas the inhibition of SIRT1 by EX-527 reversed the effect of RV on TET2 abundance. In addition, the above changes of TET2 were more significant in the nucleus than in the cytoplasm (Figures 3C,D). Meanwhile, we tested the level of $5 \mathrm{hmc}$ (red) in SH-SY5Y cells to prove the changes of enzyme activity of TET2. We found that the level of $5 \mathrm{hmc}$ was dramatically increased after EX-527 treatment (Figures 3E,F), illustrating the functional change of TET2.

\section{Deacetylation of TET2 Induced by SIRT1 Promotes TET2 Degradation via the Ubiquitin-Proteasome Pathway}

From the above experimental results, we know that the enzyme activity of SIRT1 will not affect the transcription of TET2 but affect its protein level, so we further explore whether SIRT1 will affect the degradation of TET2. Inhibition of protein synthesis with cycloheximide (CHX) demonstrated that TET2 is a rather stable protein in SH-SY5Y cells, and there was still a small amount of protein $24 \mathrm{~h}$ after inhibiting its synthesis (Figure 4A). After SRT1720 treatment, TET2 was basically completely degraded at $24 \mathrm{~h}$ in SH-SY5Y cells (Figures $4 \mathrm{~A}, \mathrm{~B}$ ), suggesting that an increased SIRT1 enzyme activity destabilizes the TET2 protein. It has been previously reported that the stability of TET proteins may be regulated by degradation pathways mediated by caspase and calpains (30). Recent findings indicate that TET2 protein may be primarily regulated through the ubiquitin-proteasome pathway in A2780, HCT116 cells (31). In our study, we found that in SH-SY5Y cells, TET2 is stabilized by the proteasome inhibitor MG-132, but not by calpains or caspase inhibitors (Figures 4C,D). In order to explore whether SIRT1 affects the protein level of TET2 through the ubiquitinated proteasome pathway, we treated cells with different concentrations of SRT1720 (Figures $4 \mathrm{E}, \mathrm{F}$ ) and $10 \mu \mathrm{M}$ of EX527 (Figures 4G,H), and added MG-132 $6 \mathrm{~h}$ before harvesting the cells. We found that with the participation of MG-132, the effect of SIRT1 enzyme activity on the TET2 protein abundance basically disappeared. In addition, EX-527 treatment, while increasing TET2 acetylation (Figure 4I), significantly reduces TET2 ubiquitination (Figure 4J). Finally, the TET2 protein that enters the ubiquitinated proteasome pathway for degradation is reduced, and the total amount of TET protein increases after EX527 treated. Consistent with this result, the protein interaction between endogenous SIRT1 and TET2 was readily detected in SH-SY5Y cells (Figure 4K). 
A

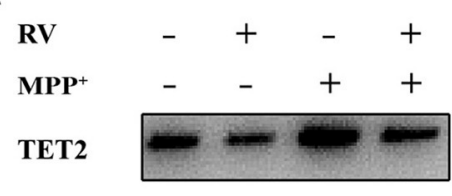

GAPDH

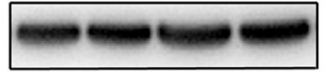

C

D

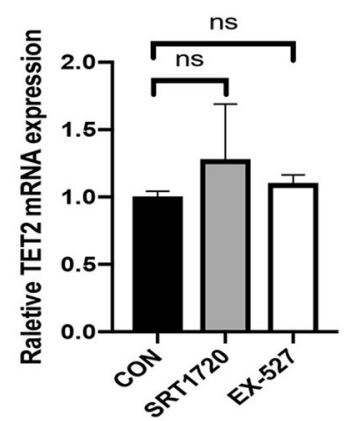

$\begin{array}{lllll}\text { SRT1720 } & 0 & 1 & 3 & 5 \mu M\end{array}$

TET2

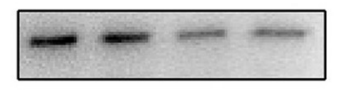

GAPDH

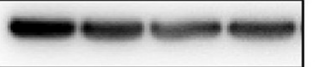

$\mathbf{F}$

$\begin{array}{lllll}\text { EX-527 } & 0 & 5 & 10 & 15 \mu M\end{array}$

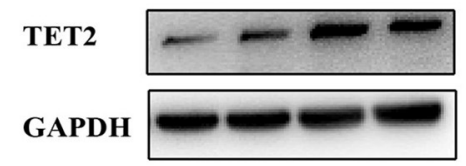

H

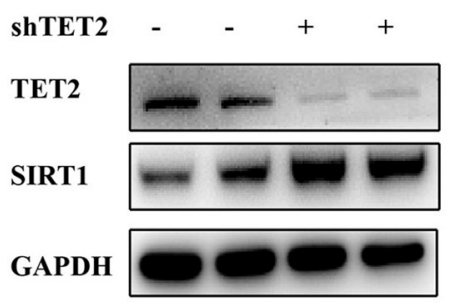

B

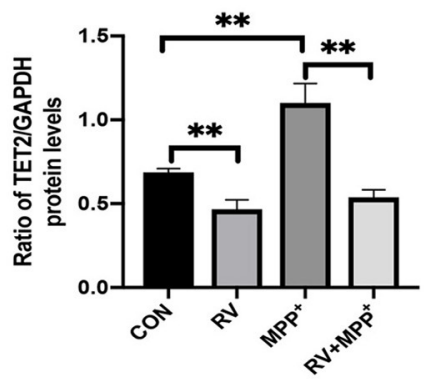

E

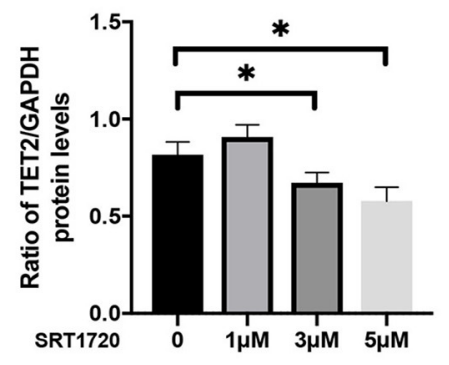

G

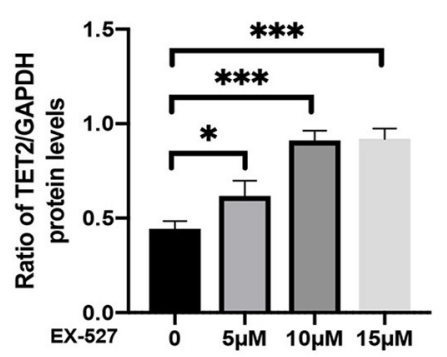

I

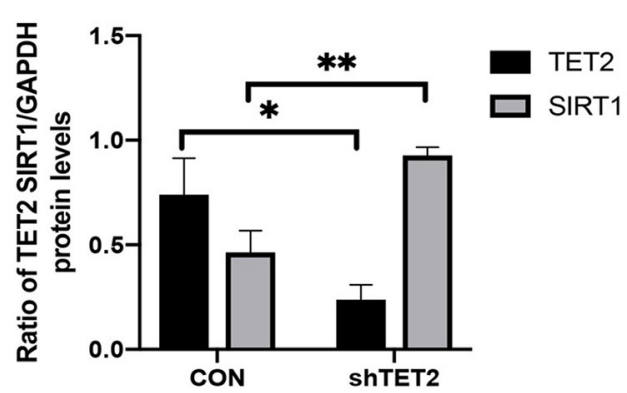

FIGURE 2 | The enzyme activity of SIRT1 is negatively correlated with the protein level of TET2. (A,B) SH-SY5Y cells were treated with MPP+ (2.5 mM), RV (resveratrol $25 \mu \mathrm{M}$ ) separately or were treated with RV $12 \mathrm{~h}$ before MPP ${ }^{+}$and then co-treated with MPP ${ }^{+}$for $24 \mathrm{~h}$. Western blot was used to detect the protein level of TET2. (C) qRT-PCR assay was used to test the mRNA level of TET2 in SH-SY5Y cells after SRT1720 (5 $\mu$ M) or EX-527 (10 $\mu$ M) were treated for $24 \mathrm{~h}$. (D-G) SH-SY5Y cells were treated with a different dose of SRT1720 or EX-527 for $24 \mathrm{~h}$ to examine the protein level of TET2. (H,I) SH-SY5Y cells were transfected with shTET2 or shNC for $48 \mathrm{~h}$. Western blot was used to detect the protein level of TET2 ${ }^{\star} P<0.05,{ }^{\star \star} P<0.01,{ }^{\star \star \star} P<0.001$. 

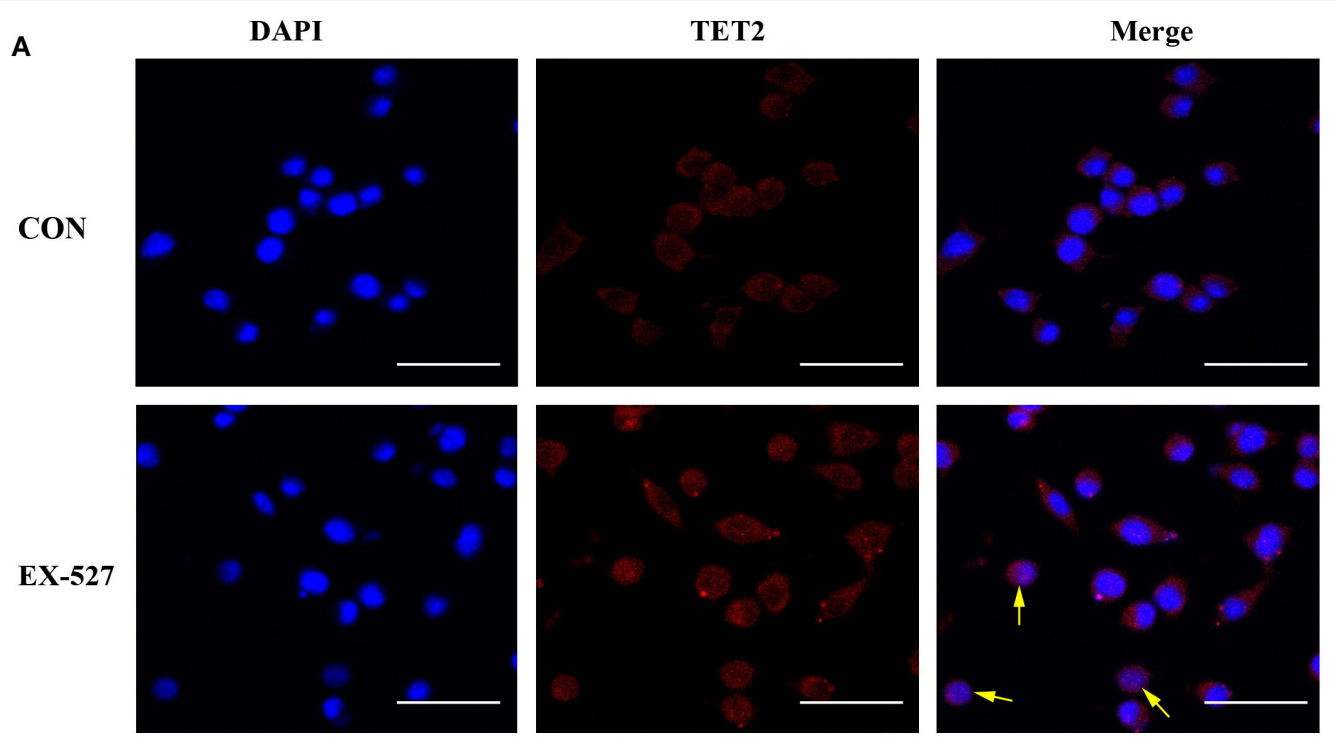

B

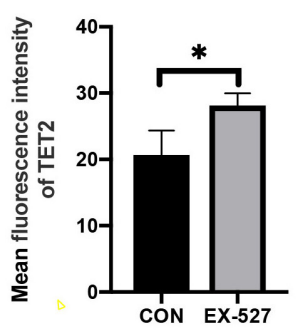

C
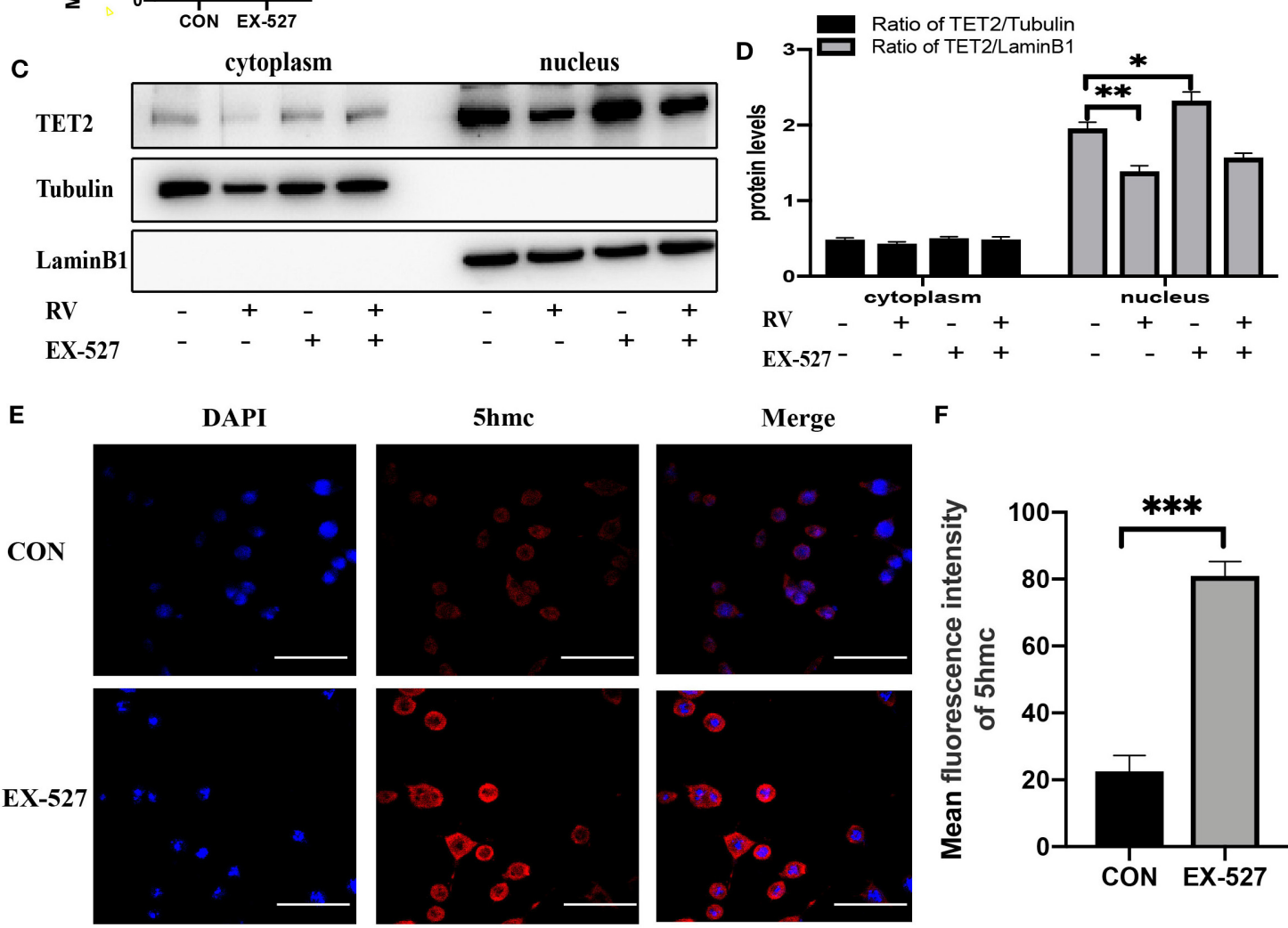

$\mathbf{F}$

FIGURE 3 | Changes in the enzyme activity of SIRT1 affected the functionality of TET2. (A,B) SH-SY5Y cells were treated with EX-527 (10 $\mu$ M) for $24 \mathrm{~h}$, and then immunofluorescence staining was performed to quantify the relative level of TET2, the yellow arrow refers to obvious nuclear transfer of TET2. Red: TET2; blue: DAPI 
FIGURE 3 | counterstaining of DNA. The fluorescence intensity of the red fluorescent was measured using the Image J software. Shown are average values with SD of triplicated experiments. Scale bar $=100 \mu \mathrm{m}{ }^{\star} P<0.05$. (C) Nuclear and cytoplasmic protein level of TET2 after specific administration. (D) The quantification of the ratio of TET2/Tubulin or TET2/LaminB1. Data are shown as the mean $\pm \mathrm{SD}(n=3)$; ${ }^{*}<0.05$, ${ }^{\star \star} P<0.01$. (E,F) Immunofluorescence staining and quantification of $5 \mathrm{hmc}$ level after treatment with EX-527 $(10 \mu \mathrm{M})$ for $24 \mathrm{~h}$. Red: $5 \mathrm{hmc}$; blue: DAPI. The fluorescence intensity of the red fluorescent was measured using the Image $\mathrm{J}$ software. Shown are average values with SD of triplicated experiments, Scale bar $=100 \mu \mathrm{m}{ }^{\star \star \star} P<0.001$.

\section{SIRT1 Influenced Neuron Growth and Cell Cycle via TET2}

Previous data from our laboratory showed that while rotenone blocks cell proliferation by arresting cells at the G0/G1 phase, SIRT1 promotes cell cycle progression to the $\mathrm{S}$ phase, thus contributing to cell proliferation (21). Moreover, TET2 also influenced the cell cycle (14). In the present study, incubation with $\mathrm{MPP}^{+}$abrogated the $\mathrm{S}$ cell cycle progression in SH-SY5Y cells, with a significant decrease of cells in the $S$ phase and a subsequent increase in cells in the G0/G1 and G2/M phases. Furthermore, this effect of $\mathrm{MPP}^{+}$was noticeably weaker after RV treatment and TET2 knockdown (Figures 5A,B). When the SIRT1 enzyme activity was inhibited by EX-527 while $\mathrm{MPP}^{+}$ treated, the proportion of cells in the $S$ phase is less than the cells treated with $\mathrm{MPP}^{+}$alone. In addition, a subsequent increase in cells in the G0/G1 and G2/M phases were more significant. These results indicate that EX-527 exacerbates the cell cycle arrest caused by $\mathrm{MPP}^{+}$. Next, we inhibited the activity of SIRT1 enzyme in the cell while reducing TET2, and the aggravation of cell cycle arrest caused by EX-527 was reduced (Figures 5C,D). Therefore, we believe that SIRT1 is likely to reduce cell cycle arrest caused by neurotoxins at least in part by regulating TET2.

\section{The CDKN2A/p16INK4a-CDK4-pRB Signaling Pathway Is Involved in the Effect of TET2 on the Cell Cycle in PD Cellular Model}

Through the above experimental results, we see that SIRT1 can regulate TET2 to influence the cell cycle. Next, we use the CCK8 experiment to observe whether the SIRT1-TET2 pathway will ultimately affect the cell death induced by $\mathrm{MPP}^{+}$. In Figure 6A, knockdown of TET2 can weaken the damage of $\mathrm{MPP}^{+}$to cells and increase cell viability. In addition to down-regulating the TET2 protein expression, we also used the TET2 enzyme activity inhibitors Bobcat339 to treat SH-SY5Y cells, and we observed that the decrease in the TET2 enzyme activity can also protect cells from neurotoxin damage (Figure 6B). When SIRT1 enzyme activity is inhibited, SH-SY5Y cells are more sensitive to the toxicity of $\mathrm{MPP}^{+}$. However, after knocking down TET2, the phenomenon of increased susceptibility of cells to $\mathrm{MPP}^{+}$caused by EX-527 basically disappeared (Figure 6C).

Our group found that after $\mathrm{MPP}^{+}$treatment, the hydroxymethylation peak of cyclin-dependent kinase inhibitor 2A (CDKN2A) gene promoter region increased by five times compared with the control group. Further research indicated that CDKN2A expression products p14ARF and p16INK4a were also significantly up-regulated, this upregulation was reversed by the knockdown of TET2 (14). CDKN2A is considered to be an important tumor suppressor gene, and it is frequently mutated or deleted in many tumors. It encodes two proteins: p16INK4a and p14ARF. Among them, the specific binding of the p16INK4a protein to cell cycle-dependent kinase 4 (CDK4) or CDK6 induces an allosteric conformational change in these proteins and inhibits the formation of the complex between CDK4 or 6 and cyclin D (32). The lack of this complex formation maintains the retinoblastoma protein $(\mathrm{Rb})$ in its hypo-phosphorylated and growth-suppressive states. This leads to the induction of the G1 phase cell cycle arrest (33).

Western blot results showed that p16INK4a was decreased after RV treated, consistent with shTET2 cells (Figures 6D,E). In contrast, the EX-527 treatment leads to an increase in the protein level of p16INK4a, and this increasing trend weakens with the decrease in TET2 expression (Figures 6F,G). After $\mathrm{MPP}^{+}$treatment, p16INK4a was significantly up-regulated, and the expression of its downstream genes CDK4 and $\mathrm{pRb}$ were significantly down-regulated. The protein expression of p16INK4a, CDK4, and pRb in SH-SY5Y cells pretreated with RV was opposite to the above-mentioned trend (Figures $6 \mathbf{H}-\mathbf{K}$ ). As shown in Figures $6 \mathrm{~L}, \mathbf{M}$, TET2 negatively regulates the expression of $\mathrm{Bcl}-2$, and knocking down TET2 can partially restore the decrease in Bcl-2 caused by $\mathrm{MPP}^{+}$treatment. Taking the above results into consideration, we hypothesized that the activation of SIRT1 by RV can reduce the cell cycle arrest of SH-SY5Y cells caused by neurotoxins through down-regulating the TET2-CDKN2A/p16INK4a-CDK4-pRB signaling pathway. On the other hand, SIRT1 may directly regulate cell apoptosis through the effect of TET2 on the expression of Bcl-2 protein.

\section{DISCUSSION}

More than 60 years have passed since George Cotzias introduced high-dose levodopa therapy in 1957 (34), we are still living in the dopamine era when it comes to the treatment of PD. At present, the pathogenesis of PD has not yet been fully elucidated, lacking of neuroprotection or disease-modifying therapy. Medicines, deep brain stimulation, and rehabilitation training can only achieve partial relief, which cannot terminate or reverse the progression of $\mathrm{PD}$. Therefore, it is urgent to explore new strategies for the treatment of PD. The pathogenesis of PD includes large-scale histone and DNA modifications, methylation and acetylation are both very important modification methods but the relationship between these two epigenetic changes is unclear.

Embryonic stem cells (ESCs) derived from SIRT6 knockout mice are skewed toward neuroectoderm development. This phenotype is associated with the depression of Oct4, Sox2, and Nanog, which in turn causes an upregulation of TET1/2 enzymes and elevated production of $5 \mathrm{hmC}$ (35). In human ovarian 
A

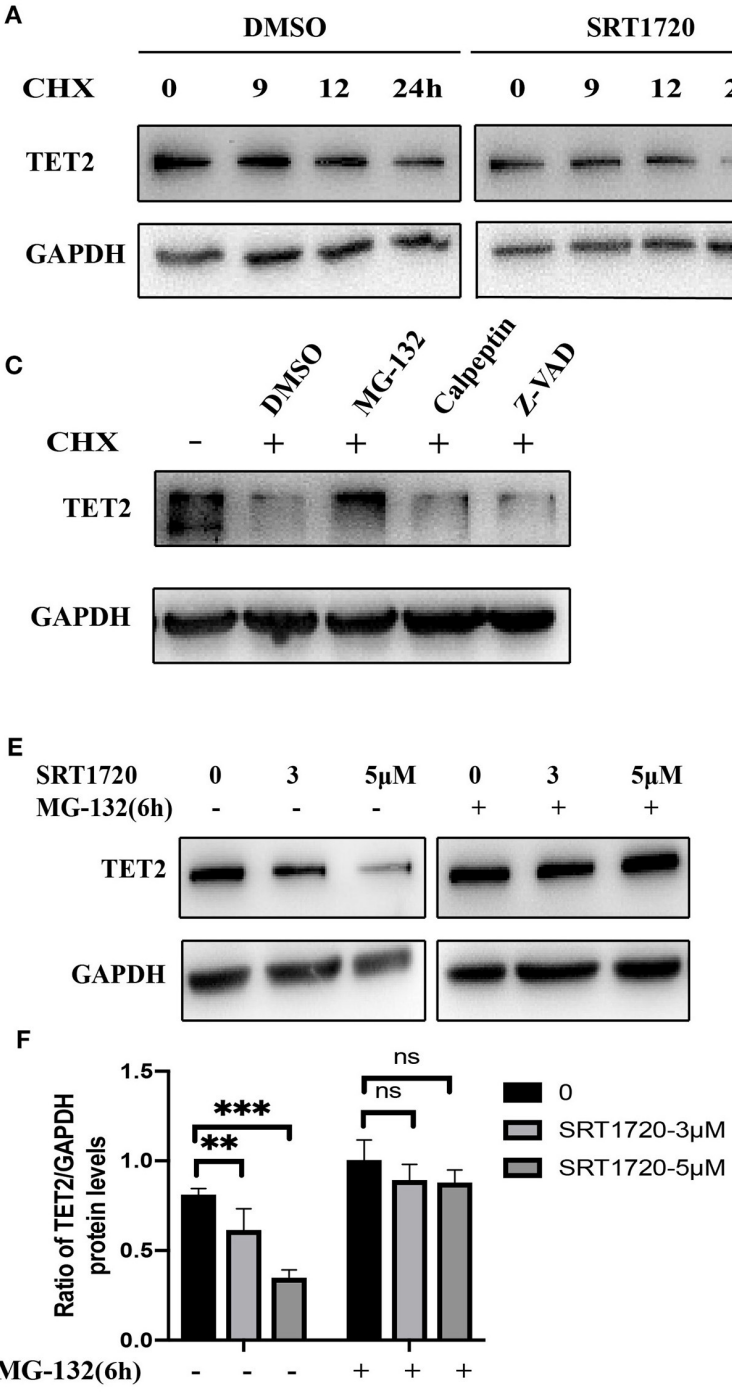

B

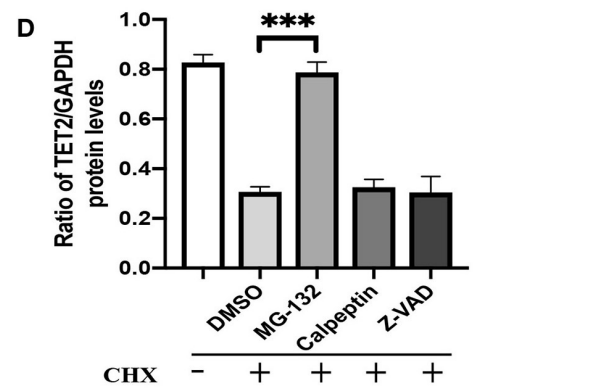

G
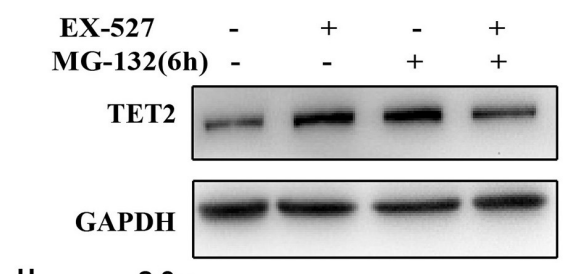

H

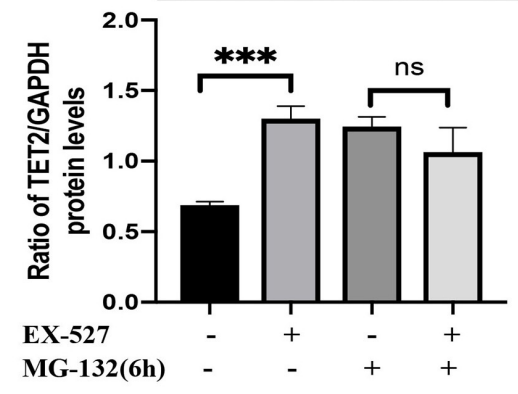

$\mathbf{K}$
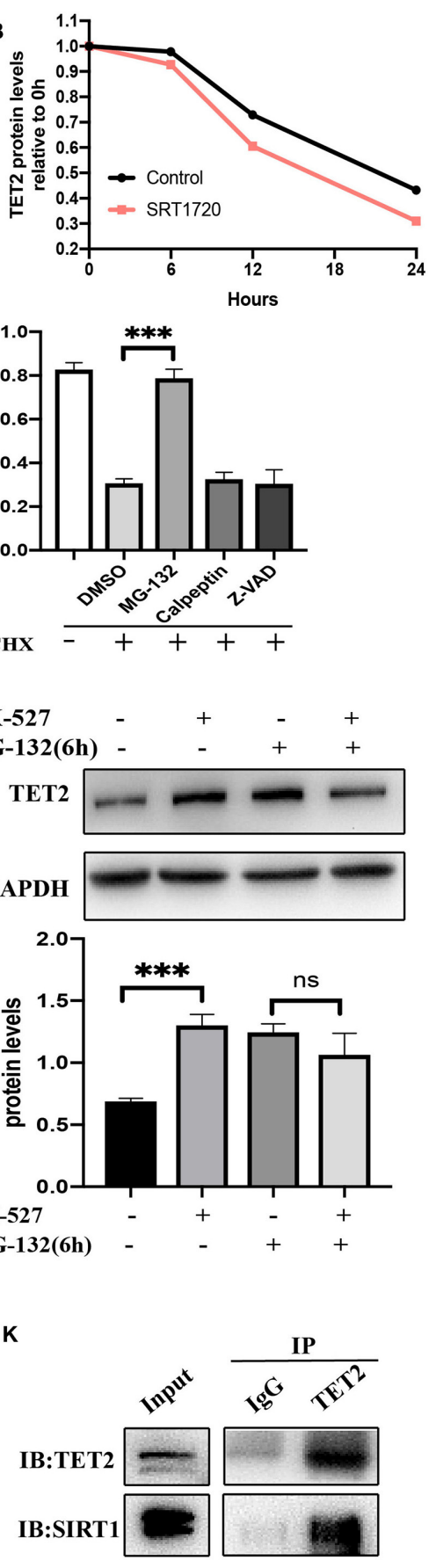

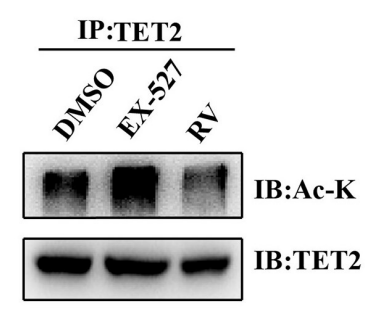

J MG-132 + +

HA-Ub $+\quad+$

EX-527 - +

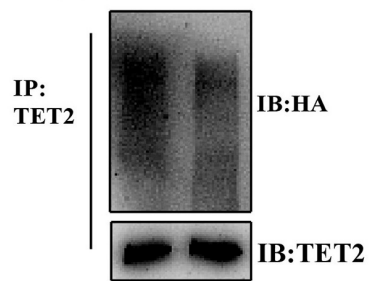



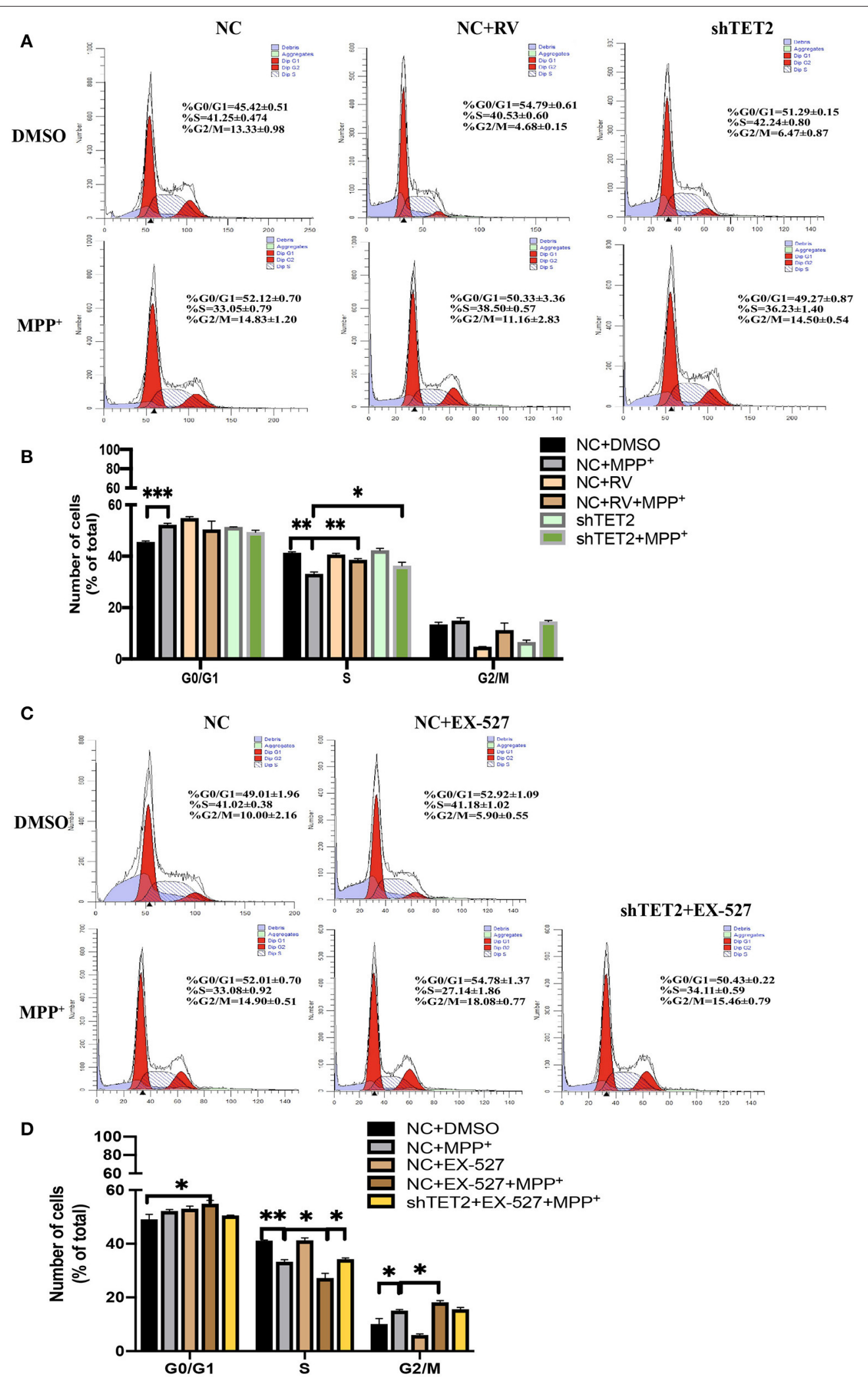

FIGURE 5 | SIRT1 influenced neuron growth and cell cycle via TET2. (A,B) SH-SY5Y cells were treated with $25 \mu \mathrm{M}$ of RV (resveratrol) for $24 \mathrm{~h}$ or transfected with shTET2 for $48 \mathrm{~h}$. shNC and DMSO was used as control. Cell cycle analysis by PI/RNAase was conducted. (C,D) SH-SY5Y cells were treated with $10 \mu \mathrm{M}$ EX-527 for $24 \mathrm{~h}$ accompanied with MPP ${ }^{+}(2.5 \mathrm{mM})$ or not. DMSO was used as control. Cell cycle analysis by PI/RNase was conducted. The cells have been transfected with shTET2 or shNC for $24 \mathrm{~h}$ before different drug treatment. Data are shown as the mean $\pm \mathrm{SD}(n=3) ;{ }^{\star} P<0.05,{ }^{\star \star} P<0.01$. 

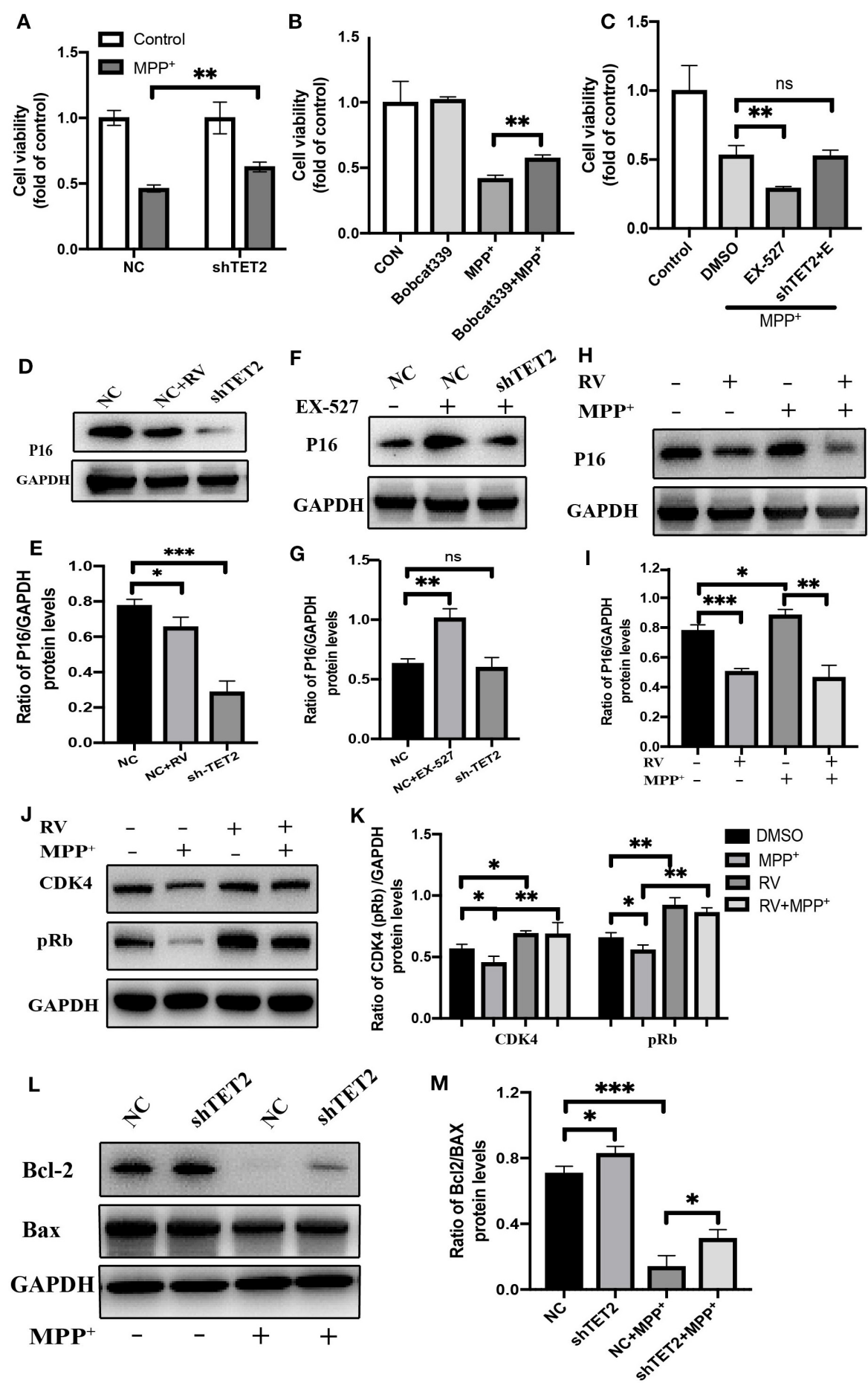

FIGURE 6 | The CDKN2A/p16INK4a-CDK4-pRB signaling pathway is involved in the effect of TET2 on the cell cycle in PD cellular model. (A,C) The cells have been transfected with shRNA or NC for $24 \mathrm{~h}$ before different drug treatment. Proliferation inhibition rates was examined by the CCK-8 method. (B) Effects of TET2 inhibitor Bobcat339 on proliferation was detected by a CCK-8 assay. Bobcat339 (3 $\mu$ M) was preincubated with cells for $12 \mathrm{~h}$ before MPP ${ }^{+}(2.5 \mathrm{mM})$ treatment. (D,E) SH-SY5Y cells were transfected with shTET2 or shNC for $24 \mathrm{~h}$ and then treated with RV (resveratrol $25 \mu \mathrm{M})$ (D,E), or EX-527(F,G) for $24 \mathrm{~h}$ then western blot was used to detect the protein level of p16 (p16INK4a). SH-SY5Y cells were treated with MPP+ $(2.5 \mathrm{mM}), \mathrm{RV}(25 \mu \mathrm{M})$ separately for $24 \mathrm{~h}$ or were treated with RV for $12 \mathrm{~h}$ before MPP+ and then co-treated with MPP ${ }^{+}$for $24 \mathrm{~h}$. Western blot and quantification of protein was performed to detect p16 (H,I) CDK4, and pRb (J,K). (L,M) The SH-SY5Y cells have been transfected with shRNA or shNC for $24 \mathrm{~h}$ before $\mathrm{MPP}^{+}(2.5 \mathrm{mM})$ treatment. Western blot and quantification of protein was performed to detect apoptotic proteins. Data are shown as the mean $\pm \mathrm{SD}(n=3) ;{ }^{\star} P<0.05,{ }^{* \star} P<0.01,{ }^{\star \star *} P<0.001$ 
cancer cells and colon cancer cells, TET2 can bind to p300 (a histone acyltransferase) and be acetylated by p300, therefore, the hydroxymethylase activity of TET2 is enhanced. HDAC1/2 can deacetylate some lysine residues of TET2 and weaken its hydroxymethylase activity. HDACs inhibitors will delay the halflife of TET2 degradation by the proteasome, thereby increasing its protein level (31). In this study, we found for the first time that there is a negative correlation between the SIRT1 enzyme activity and TET2 protein level in the in vitro model of PD. The main mechanism may be that the increase of SIRT1 enzyme activity reduces the acetylation level of TET2, and then promotes TET2 degradation through the ubiquitin-proteasome pathway, resulting in a significant reduction in the TET2 protein level. SIRT1 also affects the content of TET2 in the nucleus and $5 \mathrm{hmc}$ in SH-SY5Y cells.

Neurons are post-mitotic cells which are defined as mature cells that have ceased replication and have permanently left the cell-cycle. However, cell cycle re-entry can be seen in post-mitotic cells under certain conditions (36), for instance, in neurons following insults to the CNS, such as stroke (37), mild cognitive impairment and early AD pathology (38), Huntington's diseases, as well as other neurodegenerative diseases $(39,40)$. Yet the same activation can also be seen in healthy controls and pathologyfree neurons, though it was at lower levels (41). Restrained and limited cell cycle re-entry appears to be of use in aiding
DNA repair in neurons. Hyperploid neurons also appear to be functionally active and maintain distal axonal connections (42), suggesting that there is likely an attractive advantage for maintaining hyperploid neurons and preventing apoptosis.

There are many aspects involved in the protective effect of SIRT1 on PD DA neurons, mainly including autophagy, mitochondrial function, inflammation, and apoptosis. Our previous findings provide evidence that RV represses p53 by activating SIRT1, especially through epigenetic modulation at the transcriptional level, thus inhibiting cell cycle arrest and apoptosis. In the work published by our team a few months ago, we explored a potential role for TET2 in the pathogenesis of $\mathrm{PD}$ for the first time and found that the downregulation of the TET2 significantly attenuated cell cycle arrest and apoptosis of SH-SY5Y cells via weakening the activity of CDKN2A in $\mathrm{MPP}^{+}$-induced SH-SY5Y cells. Consistent with these results, in the present study, when the SH-SY5Y cells were incubated with $\mathrm{MPP}^{+}$, the $\mathrm{S}$ phase of cell cycle was abrogated and cells in the G0/G1 and G2/M phases were increased. Furthermore, this effect of $\mathrm{MPP}^{+}$was noticeably weaker after RV treatment and TET2 knockdown. Reducing the expression of TET2 can basically relieve the aggravation of cell cycle arrest caused by EX-527. Therefore, we believe that TET2 is also involved in the regulation of the cell cycle by SIRT1 in DA neurons. Besides, we observed the inhibitory effect of SIRT1 on apoptosis through the

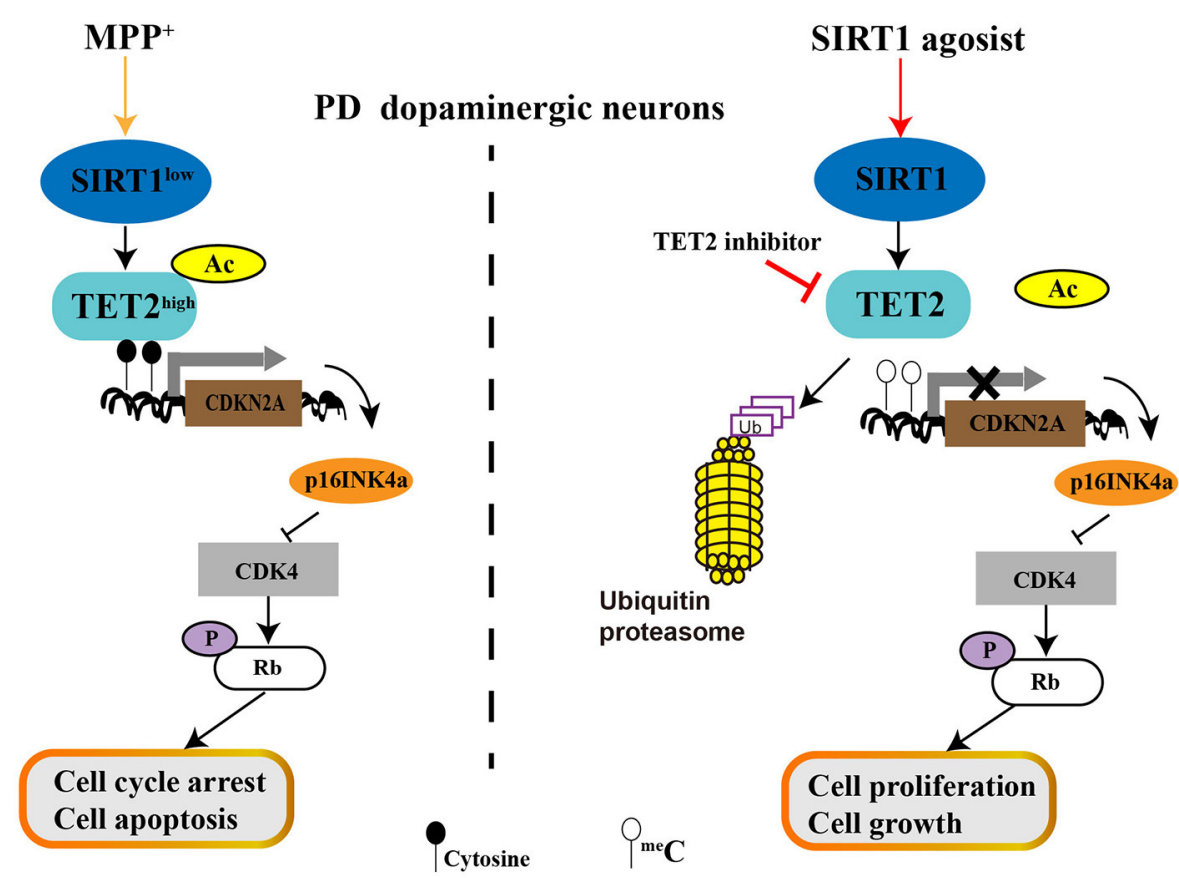

FIGURE 7 | The role of SIRT1-TET2-CDKN2A/p16INK4a pathway in dopaminergic neurons. MPP ${ }^{+}$treatment decreased SIRT1 expression and then promotes TET2 hyperacetylation, resulting in the increased stability of TET2 protein. Excess TET2 protein induce DNA demethylation and TET2 targeted gene expression, including CDKN2A. The elevated protein level of p16INK4a (One of the two proteins CDKN2A encodes) inhibit CDK4 and then reduce the pRb protein level, which allows cell cycle arrest and induces cell apoptosis of PD SH-SY5Y cells. Conversely, activation of endogenous SIRT1 by resveratrol (RV) leads to CDKN2A DNA hypermethylation due to the decreased TET2 protein levels, which relieves the inhibitory effect on CDK4 and upregulation of pRb, allowing cell proliferation and growth. Similar effects are observed for inhibition of endogenous TET2 enzyme activity with TET2 inhibitor. 
detection of Bcl-2 and Bax, and also found that RV treatment and TET2 knockdown can increase Bcl-2 protein level. Experimental results from Obexer et al. indicated that Bcl-2 protein and mRNA were markedly reduced after $48 \mathrm{~h}$ of p16INK4a expression in leukemia cells, suggesting that p16INK4a reconstitution at least in part exerts its effects via changes in the mRNA expression of Bcl-2 (43). Taken together, we think that SIRT1 may affect $\mathrm{Bcl}-2$ through the regulation of the TET2-CDKN2A/p16INK4a pathway. In addition to regulating the cell cycle progression, which suppresses growth and induces cell cycle arrest and apoptosis of DA neurons in PD, TET2 inactivation in mice fully prevents nigral dopaminergic neuronal loss induced by previous inflammation. TET2 loss also attenuates transcriptional immune responses to an inflammatory trigger (15).

It is well-known that small molecules like resveratrol and synthetic SIRT1 activators were shown to activate the enzyme directly via an allosteric site adjacent to the catalytic domain (44). Although we discuss the neuroprotection effects of resveratrol, it may also hit non-SIRT1 neuronal targets to affect biological outcomes in vivo. Therefore, in order to more specifically verify the role of SIRT1, we used SRT1720 and EX-527 as well. Moreover, we found that the down-regulation of TET2 will also lead to the up-regulation of SIRT1 (Figure 2H). This phenomenon may be caused by a negative feedback regulation between TET2 and SIRT1, and TET2 may also affect the expression of SIRT1 through some signaling pathways, but more research is required to answer this question. Therefore, we should conduct research in the $\mathrm{PD}$ in vivo model to better understand the role of SIRT1 and TET2 in the pathogenesis of PD and the relationship between these two genes.

Our finding showed that $\mathrm{MPP}^{+}$treatment decreases SIRT1 expression and then promotes TET2 hyperacetylation, resulting in the increased stability of the TET2 protein. Excess TET2 protein induce DNA demethylation and TET2 targeted gene expression, include CDKN2A. The elevated protein level of p16INK4a (One of the two proteins CDKN2A encodes) inhibit $\mathrm{CDK} 4$ and then reduce the $\mathrm{pRb}$ protein level, which allows cell cycle arrest and induces cell apoptosis of SH-SY5Y cells. Conversely, activation of endogenous SIRT1 by RV leads to CDKN2A DNA hypermethylation due to the decreased TET2 protein levels, which relieves the inhibitory effect on CDK4 and upregulation of $\mathrm{pRb}$, allowing cell proliferation and growth. Similar effects are observed for the inhibition of endogenous TET2 enzyme activity with TET2 inhibitor

\section{REFERENCES}

1. Ascherio A, Schwarzschild MA. The epidemiology of Parkinson's disease: risk factors and prevention. Lancet Neurol. (2016) 15:1257-72. doi: 10.1016/S1474-4422(16)30230-7

2. Kalia LV, Lang AE. Parkinson's disease. Lancet. (2015) 386:896912. doi: 10.1016/S0140-6736(14)61393-3

3. Feng Y, Jankovic J, Wu YC. Epigenetic mechanisms in Parkinson's disease. J Neurol Sci. (2015) 349:3-9. doi: 10.1016/j.jns.2014.12.017

4. Gasser T. Mendelian forms of Parkinson's disease. Biochim Biophys Acta. (2009) 1792:587-96. doi: 10.1016/j.bbadis.2008.12.007
(Figure 7). With the clinical and therapeutic significance, regulating the SIRT1 expression or/and SIRT1 enzyme activity is a potential therapeutic strategy for $\mathrm{PD}$, and the present study provides new possible mechanisms underlying its function. Our results further indicate that SIRT1 can affect cell cycle and apoptosis by regulating TET2 in PD progression, and targeted downregulation or inhibition of TET2 enzyme activity could be developed as a therapeutic intervention for PD, which warrants further investigation.

\section{CONCLUSIONS}

In our study, we demonstrate that RV could attenuate $\mathrm{MPP}^{+}$ induced cell cycle arrest and cell apoptosis. The underlying mechanism may include the activation of the SIRT1-TET2CDKN2A pathway. Activated endogenous SIRT1 by RV can downregulate TET2 acetylation, promoting TET2 degradation through the ubiquitinated proteasome pathway. Decreased TET2 protein level leads to CDKN2A DNA hypermethylation, the inhibitory effect of p16INK4a on CDK4 is relieved and $\mathrm{pRb}$ increases, allowing cell proliferation and growth. Inhibition of endogenous TET2 enzyme activity with TET2 inhibitor also has above effects. Therefore, the regulation of SIRT1-TET2CDKN2A signaling pathway can be applied to the treatment and intervention of PD.

\section{DATA AVAILABILITY STATEMENT}

The original contributions presented in the study are included in the article/Supplementary Material, further inquiries can be directed to the corresponding authors.

\section{AUTHOR CONTRIBUTIONS}

Y-CW and HY provided fund support, revised the manuscript, and designed project ideas. TL revised the manuscript. XL conducted the experiments and wrote the manuscript. YF, T-TW, and S-JP provided experimental materials and assist XL in problem-solving.

\section{FUNDING}

This work was supported by grants from the National Natural Science Foundation of China (Grant Number: 81971185).
5. Wirdefeldt K, Adami HO, Cole P, Trichopoulos D, Mandel J. Epidemiology and etiology of Parkinson's disease: a review of the evidence. Eur J Epidemiol. (2011) 26 Suppl.1:S1-58. doi: 10.1007/s10654-011-9581-6

6. Jowaed A, Schmitt I, Kaut O, Wullner U. Methylation regulates alphasynuclein expression and is decreased in Parkinson's disease patients' brains. J Neurosci. (2010) 30:6355-9. doi: 10.1523/JNEUROSCI.611909.2010

7. Matsumoto L, Takuma H, Tamaoka A, Kurisaki H, Date H, Tsuji S, et al. CpG demethylation enhances alpha-synuclein expression and affects the pathogenesis of Parkinson's disease. PLoS ONE. (2010) 5:e15522. doi: 10.1371/journal.pone.0015522 
8. Yu H, Su Y, Shin J, Zhong C, Guo JU, Weng YL, et al. Tet3 regulates synaptic transmission and homeostatic plasticity via DNA oxidation and repair. Nat Neurosci. (2015) 18:836-43. doi: 10.1038/nn.4008

9. Rasmussen KD, Helin K. Role of TET enzymes in DNA methylation, development, and cancer. Genes Dev. (2016) 30:733-50. doi: 10.1101/gad.276568.115

10. Kriaucionis S, Heintz N. The nuclear DNA base 5-hydroxymethylcytosine is present in Purkinje neurons and the brain. Science. (2009) 324:92930. doi: 10.1126/science.1169786

11. Coppieters N, Dieriks BV, Lill C, Faull RL, Curtis MA, Dragunow M. Global changes in DNA methylation and hydroxymethylation in Alzheimer's disease human brain. Neurobiol Aging. (2014) 35:133444. doi: 10.1016/j.neurobiolaging.2013.11.031

12. Wang F, Yang Y, Lin X, Wang JQ, Wu YS, Xie W, et al. Genome-wide loss of 5-hmC is a novel epigenetic feature of Huntington's disease. Hum Mol Genet. (2013) 22:3641-53. doi: 10.1093/hmg/ddt214

13. Gontier G, Iyer M, Shea JM, Bieri G, Wheatley EG, Ramalho-Santos $\mathrm{M}$, et al. Tet2 rescues age-related regenerative decline and enhances cognitive function in the adult mouse brain. Cell Rep. (2018) 22:197481. doi: 10.1016/j.celrep.2018.02.001

14. Wu TT, Liu T, Li X, Chen YJ, Chen TJ, Zhu XY, et al. TET2mediated Cdkn2A DNA hydroxymethylation in midbrain dopaminergic neuron injury of Parkinson's disease. Hum Mol Genet. (2020) 29:123952. doi: $10.1093 / \mathrm{hmg} / \mathrm{ddaa} 022$

15. Marshall LL, Killinger BA, Ensink E, Li P, Li KX, Cui W, et al. Epigenomic analysis of Parkinson's disease neurons identifies Tet2 loss as neuroprotective. Nat Neurosci. (2020) 23:1203-14. doi: 10.1038/s41593-020-0690-y

16. Park G, Tan J, Garcia G, Kang Y, Salvesen G, Zhang Z. Regulation of histone acetylation by autophagy in parkinson disease. J Biol Chem. (2016) 291:353140. doi: 10.1074/jbc.M115.675488

17. Finkel T, Deng CX, Mostoslavsky R. Recent progress in the biology and physiology of sirtuins. Nature. (2009) 460:587-91. doi: 10.1038/nature08197

18. Michán S, Li Y, Chou MM, Parrella E, Ge H, Long JM, et al. SIRT1 is essential for normal cognitive function and synaptic plasticity. $J$ Neurosci. (2010) 30:9695-707. doi: 10.1523/JNEUROSCI.0027-10.2010

19. Singh P, Hanson PS, Morris CM. SIRT1 ameliorates oxidative stress induced neural cell death and is down-regulated in Parkinson's disease. BMC Neurosci. (2017) 18:46. doi: 10.1186/s12868-017-0364-1

20. Robb EL, Stuart JA. trans-Resveratrol as a neuroprotectant. Molecules. (2010) 15:1196-212. doi: 10.3390/molecules15031196

21. Feng Y, Liu T, Dong SY, Guo YJ, Jankovic J, Xu H, et al. Rotenone affects p53 transcriptional activity and apoptosis via targeting SIRT1 and H3K9 acetylation in SH-SY5Y cells. J Neurochem. (2015) 134:66876. doi: $10.1111 /$ jnc. 13172

22. Guo YJ, Dong SY, Cui XX, Feng Y, Liu T, Yin M, et al. Resveratrol alleviates MPTP-induced motor impairments and pathological changes by autophagic degradation of alpha-synuclein via SIRT1-deacetylated LC3. Mol Nutr Food Res. (2016) 60:2161-75. doi: 10.1002/mnfr.201600111

23. Li X, Feng Y, Wang XX, Truong D, Wu YC. The critical role of SIRT1 in parkinson's disease: mechanism and therapeutic considerations. Aging Dis. (2020) 11:1608-22. doi: 10.14336/AD.2020.0216

24. Wu Y, Li X, Zhu JX, Xie W, Le W, Fan Z, et al. Resveratrolactivated AMPK/SIRT1/autophagy in cellular models of Parkinson's disease. Neurosignals. (2011) 19:163-74. doi: 10.1159/000328516

25. Sun J, He X, Zhu Y, Ding Z, Dong H, Feng Y, et al. SIRT1 activation disrupts maintenance of myelodysplastic syndrome stem and progenitor cells by restoring TET2 function. Cell Stem Cell. (2018) 23:355-69.e359. doi: 10.1016/j.stem.2018.07.018

26. Sun J, Zhu Y, He X, Ding Z, Dong H, Feng Y, et al. Activation of SIRT1 deacetylase as a therapeutic approach for myelodysplastic syndromes by restoring TET2 function. Blood. (2017) 130(Suppl 1), 2497. doi: 10.1182/blood.V130.Suppl_1.2497.2497

27. Cui XX, Li X, Dong SY, Guo YJ, Liu T, Wu YC. SIRT3 deacetylated and increased citrate synthase activity in PD model. Biochem Biophys Res Commun. (2017) 484:767-73. doi: 10.1016/j.bbrc.2017. 01.163
28. Huang Y, Wang G, Liang Z, Yang Y, Cui L, Liu CY. Loss of nuclear localization of TET2 in colorectal cancer. Clin Epigenetics. (2016) 8:9. doi: 10.1186/s13148-016-0176-7

29. Tahiliani M, Koh KP, Shen Y, Pastor WA, Bandukwala H, Brudno $\mathrm{Y}$, et al. Conversion of 5-methylcytosine to 5-hydroxymethylcytosine in mammalian DNA by MLL partner TET1. Science. (2009) 324:9305. doi: 10.1126/science. 1170116

30. Ko M, An J, Bandukwala HS, Chavez L, Aijö T, Pastor WA, et al. Modulation of TET2 expression and 5-methylcytosine oxidation by the CXXC domain protein IDAX. Nature. (2013) 497:122-6. doi: 10.1038/nature12052

31. Zhang YW, Wang Z, Xie W, Cai Y, Xia L, Easwaran H, et al. Acetylation Enhances TET2 function in protecting against abnormal DNA methylation during oxidative stress. Mol Cell. (2017) 65:32335. doi: 10.1016/j.molcel.2016.12.013

32. Serrano M, Hannon GJ, Beach D. A new regulatory motif in cell-cycle control causing specific inhibition of cyclin D/CDK4. Nature. (1993) 366:7047. doi: $10.1038 / 366704 \mathrm{a} 0$

33. Weinberg RA. The retinoblastoma protein and cell cycle control. Cell. (1995) 81:323-30. doi: 10.1016/0092-8674(95)90385-2

34. Carlsson A, Lindqvist M, Magnusson T. (1957) 3,4-Dihydroxyphenylalanine and 5-hydroxytryptophan as reserpine antagonists. Nature 180:1200. doi: 10.1038/1801200a0

35. Etchegaray JP, Chavez L, Huang Y, Ross KN, Choi J, Martinez-Pastor B, et al. The histone deacetylase SIRT6 controls embryonic stem cell fate via TET-mediated production of 5-hydroxymethylcytosine. Nat Cell Biol. (2015) 17:545-57. doi: 10.1038/ncb3147

36. Herrup K, Yang Y. Cell cycle regulation in the postmitotic neuron: oxymoron or new biology? Nat Rev Neurosci. (2007) 8:368-78. doi: 10.1038/nrn2124

37. Rashidian J, Iyirhiaro GO, Park DS. Cell cycle machinery and stroke. Biochim Biophys Acta. (2007) 1772:484-93. doi: 10.1016/j.bbadis.2006.11.009

38. Yang Y, Mufson EJ, Herrup K. Neuronal cell death is preceded by cell cycle events at all stages of Alzheimer's disease. J Neurosci. (2003) 23:255763. doi: 10.1523/JNEUROSCI.23-07-02557.2003

39. Nagy Z, Esiri MM, Smith AD. Expression of cell division markers in the hippocampus in Alzheimer's disease and other neurodegenerative conditions. Acta Neuropathol. (1997) 93:294-300. doi: 10.1007/s004010050617

40. Pelegr,í C, Duran-Vilaregut J, del Valle J, Crespo-Biel N, Ferrer I, Pallàs $\mathrm{M}$, et al. Cell cycle activation in striatal neurons from Huntington's disease patients and rats treated with 3-nitropropionic acid. Int J Dev Neurosci. (2008) 26:665-71. doi: 10.1016/j.ijdevneu.2008.07.016

41. Fielder E, von Zglinicki T, Jurk D. The DNA damage response in neurons: die by apoptosis or survive in a senescence-like state? J Alzheimers Dis. (2017) 60:S107-31. doi: 10.3233/JAD-161221

42. Kingsbury MA, Friedman B, McConnell MJ, Rehen SK, Yang AH, Kaushal D, et al. Aneuploid neurons are functionally active and integrated into brain circuitry. Proc Natl Acad Sci USA. (2005) 102:6143-7. doi: 10.1073/pnas.0408171102

43. Obexer P, Hagenbuchner J, Rupp M, Salvador C, Holzner M, Deutsch M, et al. p16INK4A sensitizes human leukemia cells to FAS- and glucocorticoidinduced apoptosis via induction of BBC3/Puma and repression of MCL1 and BCL2. J Biol Chem. (2009) 284:30933-40. doi: 10.1074/jbc.M109.051441

44. Hubbard BP, Gomes AP, Dai H, Li J, Case AW, Considine T, et al. Evidence for a common mechanism of SIRT1 regulation by allosteric activators. Science. (2013) 339:1216-9. doi: 10.1126/science.1231097

Conflict of Interest: The authors declare that the research was conducted in the absence of any commercial or financial relationships that could be construed as a potential conflict of interest.

Copyright (C) $2021 \mathrm{Li}, \mathrm{Liu}, \mathrm{Wu}$, Feng, Peng, Yin and Wu. This is an open-access article distributed under the terms of the Creative Commons Attribution License (CC $B Y)$. The use, distribution or reproduction in other forums is permitted, provided the original author(s) and the copyright owner(s) are credited and that the original publication in this journal is cited, in accordance with accepted academic practice. No use, distribution or reproduction is permitted which does not comply with these terms. 